\title{
PIXE Analysis of Synthetic Turf
}

\author{
Michael F. Vineyard ${ }^{1, *}$, Scott M. LaBrake ${ }^{1}$, Sajju Chalise $^{1}$, Morgan L. Clark $^{2}$, \\ Skye T. Conlan ${ }^{1}$, Zachary H. Porat ${ }^{1}$ \\ ${ }^{1}$ Department of Physics and Astronomy, Union College, Schenectady, New York, 12309, United States \\ ${ }^{2}$ Department of Physics and Astronomy, University of North Carolina, Chapel Hill, North Carolina 27599, United States
}

Copyright $\odot 2018$ by authors, all rights reserved. Authors agree that this article remains permanently open access under the terms of the Creative Commons Attribution License 4.0 International License

\begin{abstract}
We performed a proton-induced X-ray emission (PIXE) analysis of synthetic turf blade and crumb rubber infill samples to search for heavy metals and other possibly toxic substances. Samples were collected from eight FieldTurf athletic fields installed in the Capital District of New York between 2009 and 2016. The samples were bombarded with proton beams from the 1.1-MV tandem Pelletron accelerator in the Union College Ion-Beam Analysis Laboratory and the emitted X-rays were measured using a silicon drift detector with an energy resolution of about 130 eV. All of the infill samples contained $\mathrm{Zn}$ at levels above soil standards. Approximately $17 \%$ of the infill samples contained measurable concentrations of $\mathrm{Pb}$ and one had a level $(110 \pm 10 \mathrm{ppm})$ exceeding soil standards. Bromine was detected in approximately $42 \%$ of the infill samples with a maximum concentration of $1500 \pm 200 \mathrm{ppm}$ and may be due to the presence of brominated flame retardants. The distributions and relative concentrations of elements measured in synthetic turf blade samples of different colors are indicative of the metal-oxide pigments used to color the blades. For example, V and Bi observed in yellow blade samples are from the environmentally friendly, yellow pigment bismuth vanadate.
\end{abstract}

Keywords PIXE, Synthetic Turf, Heavy Metals, Bromine

\section{Introduction}

There are at least tens of thousands of synthetic turf athletic fields and playgrounds in use throughout the world. The popularity of artificial turf is due to a number of advantages over natural turf fields. They have lower maintenance costs, don't require treatment with pesticides and fertilizers, provide increased playing time, and save water. However, there have been considerable concerns in recent years about potential health effects associated with chemicals that may be released from synthetic turf (see for example Ref. [1]).
Of particular concern is the crumb rubber infill from recycled tires that is used to cushion the surfaces and support the synthetic turf blades.

High levels of volatile organic compounds and heavy metals have been measured in crumb rubber infill in a number of recent studies. Zhang et al. [2] performed a smallscale study in which they analyzed seven samples of crumb rubber and one sample of artificial grass fiber for polycyclic aromatic hydrocarbons (PAHs) using high-performance liquid chromatography (HPLC) and several heavy metals $(\mathrm{Zn}, \mathrm{Cr}, \mathrm{As}, \mathrm{Cd}$, and $\mathrm{Pb}$ ) using an inductively-coupled plasma mass spectrometer (ICP-MS) after acid digestion. Their results showed that the crumb rubber samples contained PAHs at levels above soil standards, $\mathrm{Zn}$ concentrations far exceeding soil standards, and a maximum $\mathrm{Pb}$ level of $53 \mathrm{ppm}$. Low concentrations of $\mathrm{Cr}, \mathrm{As}, \mathrm{Pb}$, and a few PAHs were measured in the artificial grass fiber sample. In a larger-scale study by Menichini et al. [3], crumb rubber samples were collected from 13 fields in Italy and analyzed for nine metals using ICP-MS and 25 PAHs using a high resolution gas chromatograph-low resolution mass spectrometer (HRGC-LRMS). They found high levels of PAHs, Zn concentrations well above soil standards, and a maximum $\mathrm{Pb}$ concentration of $46 \mathrm{mg} / \mathrm{kg}$. Marsili et al. [4] examined nine samples of crumb rubber for seven heavy metals by microwave mineralization and 14 PAHs using HPLC. Their results also show high levels of $\mathrm{Zn}$ and PAHs, and a maximum $\mathrm{Pb}$ level of about $39 \mathrm{mg} / \mathrm{kg}$.

In a recent reivew [5] of health and environmental impacts of synthetic turf, the authors point out that more data and research are needed to assess the risk presented by crumb rubber infill on the environment and human health. Last year, the U.S. Environmental Protection Agency (EPA), the Centers for Disease Control and Prevention/Agency for Toxic Substances and Disease Registry (ATSDR), and the Consumer Product Safety Commission (CPSC) launched a multi-agency study on the environmental and health effects of recycled tire crumb used on playing fields and playgrounds. 
In this paper, we report the results of a proton-induced X-ray emission (PIXE) [6] analysis of synthetic turf infill and blade samples. Concentrations were measured for elements heavier than $\mathrm{Ca}$ to search for the presence of heavy metals and toxic chemicals. Proton-induced X-ray emission is a powerful tool for the study of environmental samples because it can provide information on a broad range of elements with high sensitivity and low detection limits, and is non-destructive. Also, it often requires little or no sample preparation, unlike many chemical techniques.

\section{Materials and Methods}

\subsection{Sample Collection and Preparation}

Crumb rubber infill samples were collected at eight FieldTurf athletic fields installed in the Capital District of New York between 2009 and 2016. The samples were collected at random locations and stored in a single, clean plastic bag for each field. The crumb rubber infill typically consists of small ( $\lesssim 2-3 \mathrm{~mm}$ ) granules of shredded, recycled tires. Three pellets were prepared from the samples for each field by pressing $1 \mathrm{~g}$ of crumb rubber with approximately 1 $\mathrm{g}$ of 5-minute epoxy. The flat surfaces of the pellets were sanded and cleaned to remove epoxy from the surfaces and expose the crumb rubber infill. The pellets were mounted on a target ladder with double-sided tape for the PIXE measurements. Shown in Fig. 1 is a photograph of $1 \mathrm{~g}$ of loose infill (left) and a pellet (right).

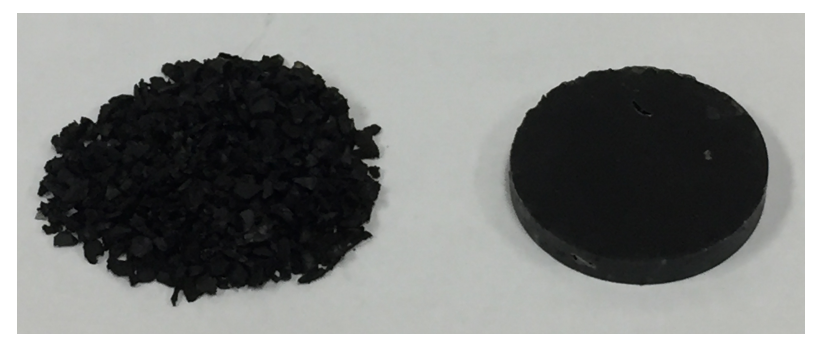

Figure 1. A photograph of $1 \mathrm{~g}$ of loose crumb rubber infill (left) and a pellet made by pressing $1 \mathrm{~g}$ of infill with approximately $1 \mathrm{~g}$ of 5-minute epoxy (right).

Samples of eight different colored synthetic grass blades were also collected from two of the athletic fields. Blades of each color were mounted on glass slides and coated with a thin layer of $\mathrm{Al}$ in a vacuum evaporator to prevent the samples from charging during the PIXE measurements. The blade samples were removed from the glass slides and taped to a target ladder for the measurements. A photograph of some of the synthetic turf blades before they were coated with a thin layer of $\mathrm{Al}$ is shown in Fig. 2.

\subsection{PIXE Experiments}

The PIXE measurements were performed with the 1.1MV tandem Pelletron accelerator in the Union College IonBeam Analysis Laboratory. Proton beams with an energy of 2.2 MeV, currents of 5-15 nA, and diameters of 1-2 mm were incident on the infill pellets and blade samples positioned in the center of a multipurpose scattering chamber. Each target was irradiated for 15-30 minutes in 5 minute intervals and the accumulated charge was estimated by removing the sample from the beam and integrating the beam current in a Faraday cup periodically for 5 minute intervals. The total charge incident on the samples ranged from 9 to $25 \mu \mathrm{C}$ with an uncertainty of less than $10 \%$. Also, a charge of $1 \mu \mathrm{C}$ was collected on $\mathrm{Ti}, \mathrm{Cr}, \mathrm{Fe}, \mathrm{Cu}, \mathrm{Ge}, \mathrm{Au}$, and $\mathrm{Pb}$ MICROMATTER standards. The X-rays emitted from the samples were detected at an angle of $135^{\circ}$ from the beam direction with an Amptek XR-100SDD silicon drift detector with a resolution of about $130 \mathrm{eV}$ and an effective solid angle of approximately $2.0 \mathrm{msr}$. An approximately $79-\mu \mathrm{m}$ thick Al foil was placed in front of the detector to suppress $\mathrm{X}$-rays from light elements. The X-ray energy spectra were analyzed using GUPIX software [7].

\section{Results}

\subsection{Infill Samples}

A typical PIXE spectrum of one of the infill samples is shown in Fig. 3. The concentrations of elements measured by fitting the spectra for the 24 infill samples with GUPIX are listed in Table 1. Concentrations are reported only for elements that are present in each sample at a $95 \%$ confidence level. The quoted uncertainties were determined by adding in quadrature the estimated uncertainty in charge integration and the fit error reported by GUPIX. All of the samples contained detectable concentrations of Fe and $\mathrm{Zn}$. The Fe concentrations ranged from $43 \pm 5$ to $800 \pm 80$ ppm, while those for $\mathrm{Zn}$ spanned from $510 \pm 50$ to $4700 \pm$ $500 \mathrm{ppm}$. A third of the samples contained Ti at concentrations ranging from $110 \pm 30$ to $640 \pm 90 \mathrm{ppm}$. Measurable concentrations of $\mathrm{Co}$ at the level of $15 \pm 2$ to $64 \pm 6 \mathrm{ppm}$ were found in approximately $42 \%$ of the samples. Approximately $42 \%$ of the samples contained $\mathrm{Ni}$ at concentrations of $4 \pm 1$ to $18 \pm 3 \mathrm{ppm}$. Concentrations of $\mathrm{Cu}$ were measured in approximately $71 \%$ of the samples at levels of 8 \pm 2 to $180 \pm 20 \mathrm{ppm}$. Approximately $42 \%$ of the samples contained $\mathrm{Br}$ at concentrations from $13 \pm 3$ to $1500 \pm$ $200 \mathrm{ppm}$. Finally, $\mathrm{Pb}$ was measured in about $17 \%$ of the samples at levels of $26 \pm 6$ to $110 \pm 10 \mathrm{ppm}$.

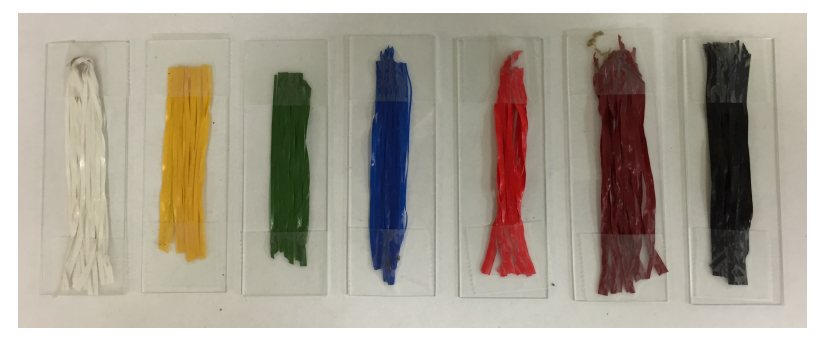

Figure 2. A photograph of some of the synthetic turf blades before they were coated with a thin layer of Al. 
Table 1. Concentrations of heavy elements measured in the infill samples.

\begin{tabular}{|c|c|c|c|c|c|c|c|c|}
\hline \multirow{2}{*}{ Sample \# } & \multicolumn{8}{|c|}{ Concentration in $\mathrm{ppm}$} \\
\hline & $\mathrm{Ti}$ & $\mathrm{Fe}$ & Co & $\mathrm{Ni}$ & $\mathrm{Cu}$ & $\mathrm{Zn}$ & $\mathrm{Br}$ & $\mathrm{Pb}$ \\
\hline 1 & $640 \pm 90$ & $250 \pm 20$ & & $10 \pm 2$ & & $4700 \pm 500$ & $110 \pm 10$ & \\
\hline 2 & & $86 \pm 9$ & $29 \pm 4$ & & & $1600 \pm 200$ & & \\
\hline 3 & & $79 \pm 8$ & $23 \pm 3$ & & & $1100 \pm 100$ & $33 \pm 6$ & $29 \pm 8$ \\
\hline 4 & $230 \pm 60$ & $800 \pm 80$ & & $18 \pm 3$ & $17 \pm 4$ & $1900 \pm 200$ & $1500 \pm 200$ & \\
\hline 5 & & $290 \pm 30$ & & & & $920 \pm 90$ & $550 \pm 60$ & \\
\hline 6 & & $280 \pm 30$ & & & & $810 \pm 80$ & & \\
\hline 7 & $110 \pm 24$ & $240 \pm 20$ & $17 \pm 3$ & $12 \pm 2$ & $120 \pm 10$ & $1300 \pm 100$ & $90 \pm 10$ & $49 \pm 8$ \\
\hline 8 & & $310 \pm 30$ & $31 \pm 3$ & $12 \pm 2$ & $110 \pm 10$ & $1000 \pm 100$ & $20 \pm 4$ & \\
\hline 9 & & $230 \pm 20$ & $43 \pm 5$ & & $17 \pm 5$ & $2000 \pm 200$ & & \\
\hline 10 & $280 \pm 30$ & $210 \pm 20$ & $15 \pm 2$ & & $25 \pm 3$ & $1600 \pm 200$ & $13 \pm 3$ & \\
\hline 11 & & $130 \pm 10$ & $64 \pm 6$ & & $19 \pm 3$ & $3500 \pm 400$ & $14 \pm 4$ & \\
\hline 12 & $500 \pm 50$ & $190 \pm 20$ & & & $76 \pm 8$ & $4000 \pm 400$ & & \\
\hline 13 & & $190 \pm 20$ & & & $9 \pm 2$ & $1000 \pm 100$ & & \\
\hline 14 & $110 \pm 30$ & $330 \pm 30$ & $53 \pm 5$ & $12 \pm 2$ & $180 \pm 20$ & $3100 \pm 300$ & & \\
\hline 15 & $280 \pm 40$ & $120 \pm 10$ & & & $51 \pm 5$ & $1200 \pm 100$ & & \\
\hline 16 & & $120 \pm 10$ & & $4 \pm 1$ & $10 \pm 2$ & $510 \pm 50$ & & $26 \pm 6$ \\
\hline 17 & & $190 \pm 20$ & & $5 \pm 1$ & $18 \pm 2$ & $1400 \pm 100$ & & \\
\hline 18 & & $160 \pm 20$ & & $5 \pm 1$ & $10 \pm 3$ & $1100 \pm 100$ & & \\
\hline 19 & & $43 \pm 5$ & $46 \pm 5$ & & $16 \pm 3$ & $1600 \pm 200$ & & \\
\hline 20 & & $49 \pm 5$ & & & $8 \pm 2$ & $780 \pm 80$ & & \\
\hline 21 & & $200 \pm 20$ & & $8 \pm 2$ & $20 \pm 4$ & $1100 \pm 100$ & & $110 \pm 10$ \\
\hline 22 & & $120 \pm 10$ & $22 \pm 4$ & & & $2600 \pm 300$ & & \\
\hline 23 & & $230 \pm 20$ & & $4 \pm 1$ & & $2800 \pm 300$ & $29 \pm 5$ & \\
\hline 24 & $230 \pm 40$ & $160 \pm 20$ & & & $12 \pm 3$ & $840 \pm 80$ & $42 \pm 6$ & \\
\hline
\end{tabular}

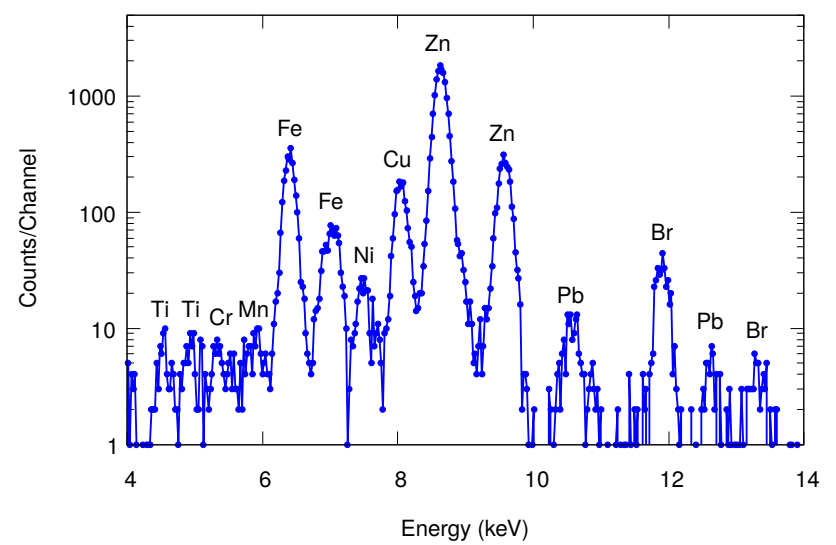

Figure 3. A PIXE spectrum taken on infill sample 7. The X-ray lines are identified. An Al filter with a thickness of $79 \mu \mathrm{m}$ was placed between the target and the detector to suppress X-rays from lighter elements.

\subsection{Blade Samples}

A PIXE spectrum from the irradiation of the yellow blade sample is shown in Fig. 4. Shown in Figure 5 is a bargraph of the elemental concentrations measured in the analysis of the synthetic blade samples. Concentrations are reported only for elements that are present in each sample at a $95 \%$ confidence level. The quoted uncertainties were determined by adding in quadrature the estimated uncertainty in charge integration and the fit error reported by GUPIX. The black blade sample contained $\mathrm{Fe}(75 \pm 8 \mathrm{ppm}), \mathrm{Cu}$ $(500 \pm 50 \mathrm{ppm})$, and $\mathrm{Zn}(21 \pm 4 \mathrm{ppm})$. Concentrations of Ti (2800 $\pm 300 \mathrm{ppm}), \mathrm{Fe}(230 \pm 20 \mathrm{ppm}), \mathrm{Cu}(800 \pm$ $80 \mathrm{ppm})$, and $\mathrm{Zn}(18 \pm 4 \mathrm{ppm})$ were measured in the blue blade sample. The garnet blade sample had measurable levels of Ti (2400 $\pm 200 \mathrm{ppm}), \mathrm{Fe}(6100 \pm 600 \mathrm{ppm}), \mathrm{Cu}(26$ $\pm 3 \mathrm{ppm})$, and $\mathrm{Zn}(16 \pm 3 \mathrm{ppm})$. Levels of Fe (11000 \pm $1000 \mathrm{ppm}), \mathrm{Cu}(210 \pm 20 \mathrm{ppm})$, and $\mathrm{Zn}(15 \pm 4 \mathrm{ppm})$ were detected in green blade sample. The purple blade sample contained $\mathrm{Ti}(3600 \pm 400 \mathrm{ppm}), \mathrm{Mn}(50 \pm 10 \mathrm{ppm}), \mathrm{Fe}$ (150 $\pm 20 \mathrm{ppm}), \mathrm{Cu}(17 \pm 3 \mathrm{ppm}), \mathrm{Zn}(770 \pm 80 \mathrm{ppm}), \mathrm{As}$ $(16 \pm 2 \mathrm{ppm})$, and $\mathrm{Sr}(37 \pm 6 \mathrm{ppm})$. Concentrations of $\mathrm{Ti}$ $(11000 \pm 100 \mathrm{ppm}), \mathrm{Fe}(180 \pm 20 \mathrm{ppm}), \mathrm{Cu}(9 \pm 2 \mathrm{ppm})$, and $\mathrm{Zn}(19 \pm 3 \mathrm{ppm})$ were measured in the red blade sample. The white blade sample contained $\operatorname{Ti}(19000 \pm 2000$ ppm), Fe (180 $\pm 20 \mathrm{ppm})$, and Zn (22 \pm 4 ppm). Finally, levels of $\mathrm{Ti}(10000 \pm 1000 \mathrm{ppm}), \mathrm{V}(1300 \pm 200 \mathrm{ppm})$, 
Fe $(110 \pm 10$ ppm), $\mathrm{Zn}(2100 \pm 200$, and $\mathrm{Bi}(2900 \pm 300$ ppm) were measured in the yellow blade sample.

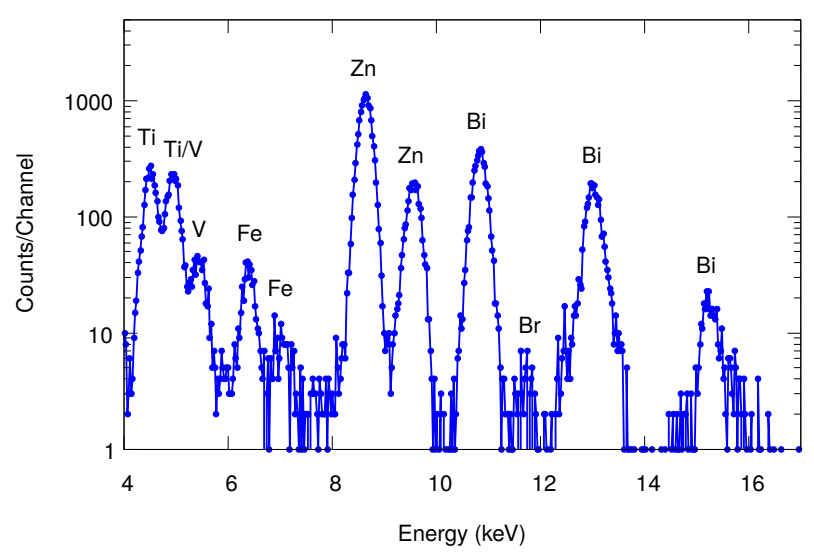

Figure 4. A PIXE spectrum taken on the yellow blade sample. The X-ray lines are identified. An $\mathrm{Al}$ filter with a thickness of $79 \mu \mathrm{m}$ was placed between the target and the detector to suppress X-rays from lighter elements.

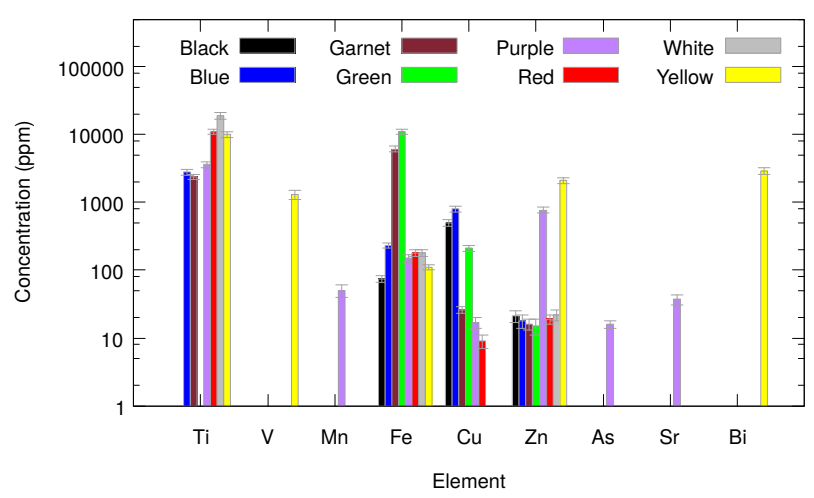

Figure 5. A bargraph of the concentrations of heavy elements measured in the turf blade samples.

\section{Discussion}

\subsection{Infill Samples}

It is clear from the broad range of measured elemental concentrations that the infill samples are not homogeneous. This is probably due to the fact that the crumb rubber infill is produced from recycled tires and other rubber from many different sources and distributed randomly over the fields.

The high concentrations of $\mathrm{Zn}$ measured in many of our infill samples are consistent with the results of other studies [2, 3, 4]. All of the infill samples had $\mathrm{Zn}$ levels exceeding the New York State Department of Conservation (NYDEC) unrestricted use soil standard of $109 \mathrm{ppm}$ and six of them exceeded the residential restricted use standard of $2200 \mathrm{ppm}$ [8]. These high levels of $\mathrm{Zn}$ are not surprising since tires contain approximately $1-2 \% \mathrm{Zn}$ by weight [9]. Zinc is not nearly as toxic to humans as other heavy metals such as $\mathrm{Pb}$, but long-term, high-dose $\mathrm{Zn}$ intoxication can interfere with the uptake of $\mathrm{Cu}$ and other essential trace elements [10]. Also, runoff with elevated levels of $\mathrm{Zn}$ may have adverse effects on aquatic wildlife and plants [11].

The range of $\mathrm{Pb}$ concentrations measured in our samples are in agreement with those reported in earlier investigations $[2,3,4]$. Only one of the four infill samples that contained measurable levels of $\mathrm{Pb}$ had a concentration above the NYDEC unrestricted use soil standard of $63 \mathrm{ppm}$ [8]. However, due to the acute toxicity of $\mathrm{Pb}$, there is no known level of exposure that is considered safe and the addition of new $\mathrm{Pb}$ to the environment should be avoided [12].

An initially surprising result is the $\mathrm{Br}$ that was detected in approximately $42 \%$ of the infill samples with a maximum concentration of $1500 \pm 200 \mathrm{ppm}$. These levels are consistent with those reported in a non peer-reviewed analysis of crumb rubber infill samples using a hand-held $\mathrm{X}$ ray fluorescence analyzer [13]. The bromine may be from flame retardants that were added to some of the tires used to make the crumb rubber or used to treat the fields [14]. Some brominated flame retardant chemicals have been linked to adverse health effects in humans. For example, polybrominated diphenyl ethers (PBDEs) are commonly used flame retardants that have been shown to reduce fertility [15] and have hormone-disrupting effects, in particular, on estrogen and thyroid hormones [16].

The concentrations of Co measured here in approximately $42 \%$ of the samples were low $(\lesssim 64 \pm 6$ ppm) and in agreement with those reported in a recent study by the European Chemicals Agency [17]. The NYDEC does not report a soil standard for Co.

All of the concentrations of $\mathrm{Ni}$ measured in this study were below the NYDEC unrestricted use soil standard of $30 \mathrm{ppm}$ [8]. Copper levels found in approximately $21 \%$ of the infill samples are above the NYDEC unrestricted use soil standard of $50 \mathrm{ppm}$, but all the measured concentrations were below the NYDEC restricted residential use soil standard of $270 \mathrm{ppm}$. Finally, the concentrations of Ti and Fe measured in the infill samples are much lower than what is typically found in soil [18].

The high levels of $\mathrm{Zn}$ and $\mathrm{Br}$, and the presence of $\mathrm{Pb}$ in some of the infill samples raises concerns about potential health risks. A recent, non peer-reviewed study of airborne particulate matter above artificial turf playing fields suggests that some of the infill particles are small enough to be inhaled [19]. Also, athletes playing on these fields often come into contact with the infill and it is possible that the particles can be ingested or that the chemicals can be absorbed through the skin.

\subsection{Blade Samples}

The distribution and relative concentrations of elements in the synthetic turf blade samples are indicative of the pigments used to color the blades. These are typically mixed metal-oxide pigments (e.g. titanium dioxide) that are mixed with the plastic polymers (nylon, polypropylene or polyethylene) before they are extruded to make the blades [20]. 
An interesting example is the $\mathrm{V}$ and Bi observed in the yellow blade sample that are from the yellow pigment bismuth vanadate $\left(\mathrm{BiO}_{4} \mathrm{~V}\right)$.

We did not detect $\mathrm{Pb}$ in any of the blade samples, unlike the results on some samples from older generation artificial turf fields $[2,21]$. The elements with high concentrations all have relatively low toxicity. Even Bi has unusually low toxicity for a heavy metal [22]. Because the pigments are mixed with the plastic polymers before the blades are extruded, the only way these chemicals could enter the body is through ingestion or if the blades deteriorate forming dust that could be inhaled.

\section{Conclusions}

We have performed a PIXE analysis of synthetic turf blade and crumb rubber infill samples collected from eight athletic fields in the Capital District of New York to search for heavy metals and other possibly toxic substances. All of the infill samples had $\mathrm{Zn}$ levels above the NYDEC unrestricted use soil standard and a quarter of them exceeded the residential restricted use standard. Bromine was detected in approximately $42 \%$ of the infill samples with a maximum concentration of $1500 \pm 200 \mathrm{ppm}$. Approximately $17 \%$ of the infill samples contained measurable concentrations of $\mathrm{Pb}$ and one had a level $(110 \pm 10 \mathrm{ppm})$ above the NYDEC unrestricted use soil standard of $63 \mathrm{ppm}$. Copper levels found in approximately $21 \%$ of the infill samples are above the NYDEC unrestricted use soil standard, but all the measured concentrations were below the NYDEC restricted residential use soil standard. The concentrations of $\mathrm{Ti}$ and Fe measured in the infill samples are much lower than what is typically found in soil. Trace amounts of $\mathrm{Co}$ and $\mathrm{Ni}$ were also found in nearly half of the samples.

The distributions and relative concentrations of elements measured in the synthetic turf blade samples of different colors are indicative of the metal-oxide pigments used to color the blades. Significant concentrations of $\mathrm{Ti}, \mathrm{Fe}, \mathrm{Cu}$, and $\mathrm{Zn}$ were measured in many of the samples. The yellow blade sample contained $\mathrm{V}$ and $\mathrm{Bi}$ from the yellow pigment bismuth vanadate. Also, trace amounts of $\mathrm{Mn}, \mathrm{As}$, and $\mathrm{Sr}$ were found in the purple blade sample.

The high concentrations of $\mathrm{Zn}$ and $\mathrm{Br}$, and the presence of $\mathrm{Pb}$ measured in the infill samples in this study validate concerns about the health risks associated with modern synthetic turf fields. Some of the infill particles may be small enough to be inhaled and transport these chemicals into the bloodstream. Also, athletes playing on these fields often come into contact with the infill and it is possible that the particles can be ingested or that the chemicals can be absorbed through the skin. The presence of these toxic elements points to the need for more in-depth health risk and environmental assessment studies to better understand the potential negative impacts of crumb rubber infill.

\section{Acknowledgements}

We would like to thank the Union College Department of Physics and Astronomy, the Union College Undergraduate Research Program, and the New York NASA Space Grant for the continued support of undergraduate research and the Union College Ion-Beam Analysis Laboratory. We also thank John Sheehan for his support in the design and fabrication of a number of instruments, and Heather Watson for help preparing the infill samples.

\section{REFERENCES}

[1] S. Shalat, Does playing on artificial turf pose a health risk for your child?, The Washington Post, March 18, 2017. Available at www.washingtonpost.com/national/healthscience/does-playing-on-artificial-turf-pose-a-health-riskfor-your-child/2017/03/17/0c61b7b4-0380-11e7-ad5bd22680e18d10_story.html?utm_term=.11054e54d2aa, accessed on July 18, 2017.

[2] J. Zhang, I. K. Han, L. Zhang, and W. Crain, Hazardous chemicals in synthetic turf materials and their bioaccessibility in digestive fluids, J. Expo. Sci. Environ. Epidemiol. 18, 600-607, 2008

[3] E. Menichini, V. Abate, L. Attias, S. De Luca, A. di Domenico, I. Fochi, G. Forte, N. Iacovella, A. L. Iamiceli, P. Izzo, F. Merli, and B. Bocca, Artificial-turf playing fields: Contents of metals, PAHs, PCBs, PCDDs and PCDFs, inhalation exposure to $\mathrm{PAHs}$ and related preliminary risk assessment, Sci. Total Environ. 409, 4950-4957, 2011.

[4] L. Marsili, D. Coppola, N. Bianchi, S. Maltese, M. Bianchi, and M. C. Fossi, Release of Polycyclic Aromatic Hydrocarbons and Heavy Metals from Rubber Crumb in Synthetic Turf Fields: Preliminary Hazard Assessment for Athletes, J. Environ. Anal. Toxicol. 5:2, 265, 2015.

[5] H. Cheng, Y. Hy, and M. Reinhard, Environmental and Health Impacts of Artificial Turf: A Review. Environ. Sci. Technol. 48, 2114-2129, 2014.

[6] S. A. E. Johansson, J. L. Campbell, and K. G. Malmqvist, Particle-Induced X-Ray Emission Spectrometry (PIXE), Wiley, New York, 1995.

[7] J. A. Maxwell, W. J. Teesdale, and J. L. Campbell, The Guelph PIXE software package II, Nucl. Instr. Meth. Phys. Res. B 95, 407-421, 1995.

[8] New York State Department of Environmental Conservation, 6 NYCRR Part 375, Environmental Remediation Programs, Table 375-6.8 (b), December 14, 2006. Available at http://www.dec.ny.gov/docs/remediation_hudson_pdf /part375.pdf, accessed on July 13, 2017.

[9] E. P. Rhodes, Z. Ren, and D. C. Mays, Zinc Leaching from Tire Crumb Rubber, Environ. Sci. Technol. 46, 1285612863, 2012. 
[10] L. M. Plum, L. Rink and H. Haase, The Essential Toxin: Impact of Zinc on Human Health, Int. J. Environ. Res. Public Health 7, 1342-1365, 2010.

[11] R. Eisler, Zinc Hazards to Fish, Wildlife and Invertebrates: A Synoptic Review, Contaminant Hazard Reviews, Report 26, US Department on the Interior Fish and Wildlife Service, Patuxent Wildlife Research Center, Laurel, MD, pp. 1-126, 1993.

[12] World Health Organization, Lead poisoning and health, 2016. Available at http://www.who.int/mediacentre/factsheets/fs379/en/, accessed on July 15, 2017.

[13] P. Dickey, Occurrence of Bromine, Lead, and Zinc in Synthetic Turf Components, Washington Toxics Coalition. Available at http://sfrecpark.org/wpcontent/uploads/rptsyntheticturftesting1007.pdf, accessed on July 15, 2017.

[14] Grassroots Environmental Education, Synthetic Turf Fields Fact Sheet, Jan. 2015. Available at https://www.grassrootsinfo.org/pdf/syntheticturf.pdf, accessed on July 15, 2017.

[15] K. G. Harley, A. R. Marks, J. Chevrier, A. Bradman, A. Sjdin, B. Eskenazi, PBDE Concentrations in Women's Serum and Fecundability, Environ. Health Perspect. 118(5), 699704, 2010.

[16] L. G. Costa and G. Giordano, Is decabromodiphenyl ether (BDE-209) a developmental neurotoxicant?, NeuroToxicology 32(1), 9-24, 2011.
[17] European Chemicals Agency, Annex XV Report: An Evaluation of the Possible Health Risks of Recycled Rubber Granules Used as Infill in Synthetic Turf Sports Fields, February 28, 2017. Available at http://www.echa.europa.eu/documents/10162/13563/annexxv_report_rubber_granules_en.pdf, accessed on July 16, 2017.

[18] E. K. Towett, K. D. Shepherd, and G. Cadisch, Quantification of total element concentrations in soils using total Xray fluorescence spectroscopy (TXRF), Sci. Total Environ. 463-464, 374-388, 2013.

[19] S. L. Shalat, An Evaluation of Potential Exposures to Lead and Other Metals as the Result of Aerosolized Particulate Matter from Artificial Turf Playing Fields, July 14, 2011. Available at http://www.nj.gov/dep/dsr/publications/artificial-turfreport.pdf, accessed July 17, 2017.

[20] TurfField, Field Building Handbook. Available at http://www.fieldturf.com, accessed on July 16, 2017.

[21] G. Van Ulirsch, K. Gleason, S. Gerstenberger, D. B. Moffett, G. Pulliam, T. Ahmed, and J. Fagliano, Evaluating and Regulating Lead in Synthetic Turf, Environ. Health Perspect. 118(10), 1345-1349, 2010.

[22] P. T. Reynolds, K. C. Abalos, J. Hopp, M. E. Williams, Bismuth Toxicity: A Rare Cause of Neurologic Dysfunction, Int. J. Clin. Med. 3, 46-48, 2012. 